\title{
Gender and socioeconomic disparities in reasons for not smoking cigarettes among Danish adolescents
}

\author{
Simone Gad Kjeld ${ }^{*} \mathbb{D}$, Stine Glenstrup and Lotus Sofie Bast
}

\begin{abstract}
Objective: To examine gender and socioeconomic differences in adolescents' reasons for not smoking cigarettes using self-reported data from Danish 14-year-olds $(N=1,559)$ collected in 2018 . $x^{2}$-tests were used to assess whether the proportion of students who rated 12 statements as important reasons for not smoking cigarettes differed according to gender and family occupational social class (OSC).

Results: More girls than boys stated that thinking the taste of cigarettes is disgusting, not being allowed to smoke by parents, knowing smoking is dangerous, not being allowed to smoke before the age of 18 , not wanting to be addicted to smoking, and that smoking makes you smell bad were important reasons for choosing not to smoke cigarettes. More boys than girls reported exercising a lot and having a partner that does not smoke as important reasons for not smoking cigarettes. More students with a high OSC compared with a low OSC stated exercising a lot and that smoking makes you smell bad were important reasons. In conclusion, reasons for not smoking cigarettes differed substantially across gender and less according to socioeconomic position.
\end{abstract}

Keywords: Smoking, Cigarettes, Adolescents, Reasons, Motivations, Smoking prevention, Tobacco, Non-smoking

\section{Introduction}

In a smoking preventive perspective, increased knowledge about gender and socioeconomic disparities in reasons for not smoking may help developing initiatives to reduce the youth tobacco incidence-and consequently, narrowing the social inequalities in health. Generally, individuals with a lower socioeconomic position are more likely to start smoking in adolescence and less likely to quit smoking in adulthood $[1,2]$; thus, contributing to social disparities in smoking and in health. An increasing priority of smoking preventive measures is to equalize socioeconomic disparities in smoking [3, 4]. However, these efforts might be challenged because

*Correspondence: simk@sdu.dk

National Institute of Public Health, University of Southern Denmark,

Studiestraede 6, 1455 Copenhagen K, Denmark health interventions are sometimes easier adopted by individuals from higher socioeconomic backgrounds [5].

Furthermore, research shows that boys are more attracted to smoking cigarettes compared with girls [6, 7]. In a recent study, we found that girls have more positive attitudes towards several elements of smoking prevention initiatives (e.g., rules for smoking at school) [8]. Hence, gender differences exist in both smoking uptake and in the adoption of smoking preventive initiatives.

Research has found adolescents' main reasons to stay tobacco free were the negative impact of smoking on health, that smoking is disgusting, and that smoking smells bad [9]. Another study found doing sports and getting yellow teeth were important reasons for not smoking-in addition to health concerns and bad smell of cigarettes [10]. Moreover, research indicates non-smoking adolescents have more knowledge about health-related issues due to smoking compared with 
adolescents who smoke cigarettes [11]. Studies focusing on socioeconomic and gender differences in reasons for not smoking are, however, very limited. One qualitative study indicated non-smoking boys and girls did not differ markedly in their attitudes towards smoking and across gender, concerns about health and a positive self-image were important reasons for not smoking [12].

Insights into gender and socioeconomic disparities in reasons for not smoking is essential-both for shaping smoking preventive interventions to ensure they reach all adolescents as well as for understanding which parameters may equalize gender and socioeconomic disparities in smoking-and consequently in health. Therefore, the aim of this study was to investigate whether there are gender and socioeconomic disparities in which reasons adolescents' rate as important for not smoking cigarettes.

\section{Main text \\ Methods \\ Study design}

In this study, we used data from the X:IT II intervention, a multi-component intervention aiming at preventing smoking uptake among adolescents in the school [3]. The Danish Cancer Society developed the intervention and its effectiveness was evaluated by the Centre for Intervention Research, University of Southern Denmark from September 2017 until June 2020. From 31 municipalities across Denmark, 300 schools were randomly selected and invited to participate in the study of which 57 schools were eligible for enrollment. After enrollment, 11 schools withdrew from the study due to reasons mainly centering around lack of time and other priorities which left 46 schools that were included at baseline. The enrolled students were followed from the beginning of 7 th grade (baseline measurement) until the end of 9th grade (third follow-up measurement), thus, including students from 13 to 15 years of age [3].

Students' responses to the first follow-up questionnaire were used after initiation of the X:IT II intervention (collected at the end of 7th grade). In total, 44 schools were included in this follow-up measurement as two schools withdrew their participation after the baseline data collection. All students (around 14 years of age) at the schools were encouraged to participate in the data collection which consisted of an internet-based self-reported questionnaire that the students could fill in during school hours with instructions by their teachers. The questionnaire included topics related to students' as well as their families' and friends' tobacco patterns, attitudes and norms towards smoking, sociodemographic items, items about their well-being, and items about the X:IT II intervention and its components.
Of all eligible students $(n=2228), 74.8 \%(n=1666)$ answered the questionnaire. Due to a small number of students identifying as neither a boy nor a girl in the data material $(1.6 \%, n=27)$, the group was excluded for further analyses in this study. We also excluded students who currently smokes cigarettes $(4.8 \%, \mathrm{n}=80)$ as the focus of this study was adolescents' reasons for not smoking cigarettes. Thus, the total study sample here was $\mathrm{N}=1,559$ (70.0\% of eligible students).

\section{Measures}

Gender was assessed by asking the question "are you a boy or a girl?" divided into $1=$ boy, $2=$ girl, or $3=$ students who felt they did not fit into neither of the two first categories. Students in category 3 were excluded for further analyses.

Family occupational social class (OSC) was determined by two questions concerning the occupations of students' father and mother. OSC was coded in accordance with the Danish Occupational Social Class Measurement [13]. Information about parental occupation was categorized from $\mathrm{I}=$ high to $\mathrm{V}=$ low social class as well as $\mathrm{VI}=$ parents receiving social benefits. The parent ranking highest determined the OSC of parents. In this study, OSC was recoded into three categories: $1=$ high (I-II), $2=$ medium (III-IV), $3=$ low $(\mathrm{V}-\mathrm{VI})$, and $4=$ nonclassifiable. Students with a non-classifiable OSC (14.3\%) were excluded in the main analyses of the associations between reasons for not smoking and OSC.

Reasons for not smoking included twelve statements addressing students who currently do not smoke cigarettes. Students had to rank each statement as either $1=a$ very important reason for not smoking, $2=$ an important reason for not smoking, $3=$ not an important reason for not smoking, and $4=$ not an important reason for smoking at all. The variables were dichotomized into $1=$ important reason $(1+2)$ and $2=$ not important reason $(3+4)$. The statements are outlined in Table 2.

\section{Analyses}

The 9.4 version of SAS was used for the statistical analyses. We compared the distributions of variables concerning reasons for not smoking in relation to students' gender and OSC assessed by $\chi^{2}$-tests. A $p$-value of $<0.05$ was considered statistically significant.

\section{Results}

As presented in Table 1, almost half of the respondents were girls (51.3\%). Concerning family occupational social class (OSC), $38.0 \%$ of the students had a high OSC, while $39.0 \%$ had a medium, $8.6 \%$ had a low, and $14.3 \%$ had a non-classifiable OSC (see also Table 1 for all student characteristics). 
Table 1 Characteristics of students $(\mathrm{N}=1,559)$

\begin{tabular}{lrr}
\hline Student characteristics & $\%$ & $\mathbf{n}$ \\
\hline Girls & 51.3 & 746 \\
Family occupational social class (OSC) & & \\
High & 38.0 & 542 \\
Medium & 39.0 & 556 \\
Low & 8.6 & 123 \\
Non-classifiable & 14.3 & 204 \\
Ethnicity & & \\
Danish origin & 92.6 & 1102 \\
Descendants of immigrants & 4.0 & 47 \\
Immigrants & 2.0 & 24 \\
Non-classifiable & 1.4 & 17 \\
Family structure & & \\
Lives with two biological parents & 68.6 & 1059 \\
Single-parent family & 8.0 & 124 \\
Reconstituted family & 16.3 & 252 \\
Other (e.g., foster care or institution) & 7.0 & 108 \\
Ever smoked cigarettes & 9.9 & 162 \\
Parental smoking & 31.9 & 493 \\
Best friend's smoking & 10.4 & 160 \\
Other friends'smoking & 28.5 & 437 \\
Binge drinking within the last month & 17.7 & 274 \\
Ever tried electronic cigarettes & 9.4 & 146 \\
Ever tried snus & 1.4 & 21 \\
Ever tried water pipe & 6.5 & 100 \\
\hline
\end{tabular}

In Table 2, the proportion of students who reported each of the 12 statements as important reasons for not smoking were compared across gender and OSC. Overall, knowing smoking is dangerous, not wanting to be addicted to smoking, smoking makes you smell bad, and smoking cigarettes is not interesting were most frequently reported as important reasons for not smoking across OSC and gender.

Results show that more girls than boys reported thinking the taste of cigarettes is disgusting (girls: $70.0 \%$, boys: $61.8 \%, p=0.002$ ), not being allowed to smoke by their parents (girls: $80.1 \%$, boys: $71.0 \%, p<0.001$ ), knowing smoking is dangerous (girls: $96.3 \%$, boys: $89.8 \%$, $p<0.001)$, not being allowed to smoke before the age of 18 (girls: $63.9 \%$, boys: $56.8 \%, p=0.009$ ), not wanting to be addicted to smoking (girls: $90.6 \%$, boys: $83.7 \%, p<0.001$ ), and that smoking makes you smell bad (girls: $87.6 \%$, boys: $61.8 \%, p=0.002$ ) were important reasons for not smoking. On the other hand, more boys than girls reported exercising a lot (girls: $70.0 \%$, boys: $61.8 \%, p=0.002$ ) and having a partner that does not smoke (girls: $70.0 \%$, boys: $61.8 \%, p=0.002)$ as important reasons for not smoking cigarettes.

We found that more students with a high OSC compared with a low OSC reported exercising a lot (high OSC: $67.3 \%$, low OSC: $57.4 \%, p=0.013$ ) and that smoking makes you smell bad (high OSC: $86.5 \%$, low OSC: $75.9 \%$, $p=0.022$ ) were important reasons for not smoking.

\section{Discussion}

This study is among the few which have studied gender and socioeconomic differences in young people's reasons for not smoking cigarettes. We found that students' reasons for not smoking differed quite substantially across gender, while the differences were less clear across socioeconomic positions.

Across gender and socioeconomic positions, we found that students frequently reported knowing smoking is dangerous, not wanting to be addicted to smoking,

Table 2 Proportion of boys and girls as well as students with a high, medium, and low OSC who have reported each of the twelve statements as important reasons for not smoking

\begin{tabular}{|c|c|c|c|c|c|c|c|}
\hline & Boys (\%) & Girls (\%) & $p$-value & High OSC (\%) & $\begin{array}{l}\text { Medium } \\
\text { OSC (\%) }\end{array}$ & Low OSC (\%) & $p$-value \\
\hline None of my friends smoke & 39.2 & 34.5 & 0.081 & 36.5 & 36.1 & 36.4 & 0.994 \\
\hline I think the taste of cigarettes is disgusting & 61.8 & 70.0 & 0.002 & 68.9 & 65.0 & 60.2 & 0.159 \\
\hline I am not allowed to smoke by my parents & 71.0 & 80.1 & $<0.001$ & 79.2 & 74.4 & 72.1 & 0.111 \\
\hline I think smoking is too expensive & 79.2 & 77.0 & 0.349 & 78.7 & 75.5 & 78.2 & 0.475 \\
\hline I know smoking is dangerous & 89.8 & 96.3 & $<0.001$ & 95.4 & 91.4 & 92.7 & 0.043 \\
\hline Smoking is not interesting & 82.1 & 84.1 & 0.341 & 82.2 & 84.0 & 81.8 & 0.692 \\
\hline You are not allowed to smoke before the age of 18 & 56.8 & 63.9 & 0.009 & 60.2 & 58.1 & 67.9 & 0.164 \\
\hline I exercise a lot & 65.4 & 59.6 & 0.033 & 67.3 & 58.9 & 57.4 & 0.013 \\
\hline I like making my own decisions & 64.3 & 66.3 & 0.447 & 65.0 & 66.8 & 58.7 & 0.275 \\
\hline My partner does not smoke & 40.0 & 31.8 & 0.003 & 35.4 & 35.4 & 32.1 & 0.796 \\
\hline I do not want to be addicted to smoking & 83.7 & 90.6 & $<0.001$ & 89.8 & 84.5 & 86.2 & 0.044 \\
\hline Smoking makes you smell bad & 81.0 & 87.6 & 0.001 & 86.5 & 83.4 & 75.9 & 0.022 \\
\hline
\end{tabular}

$p$-values are marked with italics when significant at the $5 \%$ level 
thinking smoking makes you smell bad, and smoking cigarettes is not interesting as important reasons for not smoking cigarettes. These findings are consistent with existing literature which have indicated health concerns and the bad smell of cigarettes as main reasons for not smoking cigarettes among the youth [9]. Moreover, research indicated that thinking cigarettes are disgusting was an additional important reason for not smoking [9, 10], while in this study, this reason was mostly reported as important by girls.

The only identified study addressing gender differences in reasons for not smoking indicated that concerns about health were equally important reasons for not smoking across gender [12]. In contrast, our study found girls more often than boys reported knowing smoking is dangerous and not wanting to be addicted to smoking as important reasons for not smoking. This might be due to boys not having the same risk assessment about the danger of smoking [14] or other factors may be more important for boys' motivations to not smoke. For example, in this study, boys reported exercising a lot was an important reason for not smoking. In this connection, a study found that boys smoking cigarettes were especially concerned about the effect of smoking on their fitness and sport, while girls were more concerned about the smell of cigarettes [15].

More girls than boys reported in this study that regulations about smoking (i.e., not being allowed to smoke by parents and not being allowed to smoke before the age of 18) were important reasons for not smoking. These findings are in line with existing research indicating that girls and young females have more positive attitudes towards smoking regulations-both at the societal and school level as well as at home $[8,16]$.

We did not find substantial differences across socioeconomic positions in reasons for not smoking, although there was a tendency to more students with a high OSC reporting exercising a lot as an important reason for not smoking. This relates to existing literature indicating that adolescents with higher socioeconomic positions are more physically active [17]; thus, being physically active may impact students' decisions about smoking. Thinking smoking makes you smell bad was also an important reason for not smoking among adolescents with a high OSC relative to adolescents with a medium or low OSC. More research about socioeconomic disparities in reasons for not smoking is needed to qualify these findings.

\section{Limitations}

An important strength of this study is the school-based evaluation design-as most children and adolescents attends public or private schools in Denmark, the possibility of reaching all students regardless of gender and socioeconomic positions is high. Nonetheless, this study may also have some limitations.

One limitation of this study may be that a specific group of adolescents are more likely to answer the questionnaire than others; thus, this study may have some degree of self-selection bias. In a recent study, however, we found that schools participating in the X:IT II study were not markedly different compared with all schools in Denmark on several parameters, including organizational resources, student enrollment, ethnic composition, average grades, and academic well-being. The biggest difference seemed to be that more public schools than private schools participated in the X:IT II study [18].

In this study, we used self-reported data from students as we believe that this information provides the most indepth insights into adolescents' everyday lives. Validation studies have found that adolescents' self-reporting of smoking is consistent with biochemical measures of tobacco consumption [19-21]. However, these studies also indicated that a group of adolescents who reported not to smoke may in fact be smoking.

Another limitation may be that students were only able to assess whether they believed the 12 statements were important reasons for not smoking. Because students were not able to write if they considered other reasons for not smoking important, we may have missed some important information.

Approximately $14 \%$ of the students were categorized with a non-classifiable OSC and in this study, we chose to exclude this group from the analyses due to the heterogeneity of the group. The proportion of students that could not be classified within the low, medium, or high OSC groups may bias our findings and therefore, we recommend that future research will further investigate how reasons for not smoking potentially differ across socioeconomic positions.

Abbreviations

OSC: Family occupational social class.

\section{Acknowledgements}

The X:IT Project group would like to thank all participating schools, students, parents, teachers, and principals.

\section{Authors' contributions}

SGK, SG, and LBS conceptualized and designed this study. SGK carried out the main analyses and drafted the initial manuscript. SG and LBS critically reviewed and revised the manuscript. All authors read and approved the final manuscript.

\section{Funding}

This study was funded by the Danish Cancer Society.

\section{Availability of data and materials}

Data that support the findings of this study are available from University of Southern Denmark (SDU). Restrictions apply to the availability of data which were used under license for the current study and are thus, not publicly 
available. However, data are available from the corresponding author upon reasonable request and with permission of SDU.

\section{Ethics approval and consent to participate}

Although there is no formal institution for ethical assessment and approval of questionnaire-based population studies in Denmark, the X:IT II study was approved by the SDU Research and Innovation Organization. Moreover, the study is registered at the Danish Data Protection Agency (Reference Number 2015-57-0008). Parents of the students both received written information sent out by the schools and were verbally informed at a parents-teacher meeting about the purposes of this study and that participation of their child was voluntary. Students were also verbally informed by the teachers before answering the questionnaires and written information about the study was provided in the beginning of the questionnaire, including that their participation was voluntary, and their answers would be treated with confidence.

\section{Consent for publication}

Not applicable.

\section{Competing interests}

The authors declare that they have no competing interests.

Received: 12 November 2020 Accepted: 16 January 2021

Published online: 23 January 2021

\section{References}

1. Green MJ, Leyland AH, Sweeting H, Benzeval M. Socioeconomic position and early adolescent smoking development: evidence from the British Youth Panel Survey (1994-2008). Tob Control. 2016;25(2):203-10.

2. Hiscock R, Dobbie F, Bauld L. Smoking cessation and socioeconomic status: an update of existing evidence from a national evaluation of English stop smoking services. Biomed Res Int. 2015;2015:274056.

3. Bast LS, Due P, Lauemøller SG, Kjær NT, Christiansen T, Andersen A. Study protocol of the X: IT II-a school-based smoking preventive intervention. BMC Public Health. 2019;19(1):497.

4. Tinner L, Caldwell D, Hickman M, MacArthur GJ, Gottfredson D, Perez $A L$, et al. Examining subgroup effects by socioeconomic status of public health interventions targeting multiple risk behaviour in adolescence. BMC Public Health. 2018;18(1):1180.

5. Moore GF, Littlecott HJ, Turley R, Waters E, Murphy S. Socioeconomic gradients in the effects of universal school-based health behaviour interventions: a systematic review of intervention studies. BMC Public Health. 2015;15(1):907.

6. Wellman RJ, Dugas EN, Dutczak H, O'Loughlin EK, Datta GD, Lauzon B, et al. Predictors of the onset of cigarette smoking: a systematic review of longitudinal population-based studies in youth. Am J Prev Med. 2016;51(5):767-78.

7. Geckova A, Van Dijk J, van Ittersum-Gritter T, Groothoff J, Post D. Determinants of adolescents' smoking behaviour: a literature review. Cent Eur J Public Health. 2002:10(3):79.

8. Lund L, Lauemøller SG, Kjeld SG, Andersen A, Bast LS. Gender differences in attitudes towards a school-based smoking prevention intervention. Scand J Public Health. 2020. https://doi.org/10.1177/1403494820953325.

9. Kaya ÇA, Ünalan PC. Factors associated with adolescents'smoking experience and staying tobacco free. Ment Health Fam Med. 2010;7(3):145.

10. Hayes ER, Plowfield LA. Smoking too young: students' decisions about tobacco use. MCN Am J Matern Child Nurs. 2007;32(2):112-6.

11. Haddad C, Sacre H, Hajj A, Lahoud N, Akiki Z, Akel M, et al. Comparing cigarette smoking knowledge and attitudes among smokers and nonsmokers. Environ Sci Pollut Res Int. 2020;27:1-11.

12. Kulbok PA, Rhee H, Botchwey N, Hinton I, Bovbjerg V, Anderson NLR. Factors influencing adolescents' decision not to smoke. Public Health Nurs. 2008;25(6):505-15.

13. Christensen U, Krølner R, Nilsson C, Lyngbye P, Hougaard C, Nygaard E, et al. Addressing social inequality in aging by the Danish Occupational Social Class Measurement. J Aging Health. 2014;26(1):106-27.

14. Lundborg P, Andersson H. Gender, risk perceptions, and smoking behavior. J Health Econ. 2008;27(5):1299-311.

15. Amos A, Bostock Y. Young people, smoking and gender-a qualitative exploration. Health Educ Res. 2007;22(6):770-81.

16. Ellis JA, Perl SB, Davis K, Vichinsky L. Gender differences in smoking and cessation behaviors among young adults after implementation of local comprehensive tobacco control. Am J Public Health. 2008;98(2):310-6.

17. Borraccino A, Lemma P, lannotti R, Zambon A, Dalmasso P, Lazzeri G, et al. Socio-economic effects on meeting PA guidelines: comparisons among 32 countries. Med Sci Sports Exerc. 2009;41(4):749.

18. Kjeld SG, Lauemøller SG, Lund L, Andersen A, Bast LS. School characteristics and participation in a smoking prevention intervention. Health Behav Policy Rev. 2020;7(3):170-8.

19. Kentala J, Utriainen P, Pahkala K, Mattila K. Verification of adolescent selfreported smoking. Addict Behav. 2004;29:405-11.

20. Caraballo RS, Giovino GA, Pechacek TF. Self-reported cigarette smoking vs. serum cotinine among U.S. adolescents. Nicotine Tob Res. 2004;6:19-25.

21. Dolcini MM, Adler NE, Lee P, Bauman KE. An assessment of the validity of adolescent self-reported smoking using three biological indicators. Nicotine Tob Res. 2003;5:473-83.

\section{Publisher's Note}

Springer Nature remains neutral with regard to jurisdictional claims in published maps and institutional affiliations.
Ready to submit your research? Choose BMC and benefit from:

- fast, convenient online submission

- thorough peer review by experienced researchers in your field

- rapid publication on acceptance

- support for research data, including large and complex data types

- gold Open Access which fosters wider collaboration and increased citations

- maximum visibility for your research: over 100M website views per year

At $\mathrm{BMC}$, research is always in progress.

Learn more biomedcentral.com/submissions 